\title{
The Effects of Intravenous Injection of $\alpha$-Human Atrial Natriuretic Polypeptide on Blood Pressure, Renal Hemodynamics and Urinary Kinin Excretion in Anesthetized Rabbits
}

\author{
Noboru Nushiro, Keishi Abe, Masahide Seino, Ken \\ Omata and Kaoru Yoshinaga \\ The Second Department of Internal Medicine, Tohoku \\ University School of Medicine, Sendai 980
}

\begin{abstract}
Nushiro, N., Abe, K., Seino, M., Omata, K. and Yoshinaga, K. The Effects of Intravenous Injection of $\alpha$-Human Atrial Natriuretic Polypeptide on Blood Pressure, Renal Hemodynamics and Urinary Kinin Excretion in Anesthetized Rabbits. Tohoku J. exp. Med., 1987, 151 (2), 221-231 — Studies were performed in anesthetized rabbits to examine the effects of $\alpha$-human atrial natriuretic polypeptide $(\alpha$-hANP) on blood pressure, renal hemodynamics and urinary kinin excretion. Intravenous bolus injection of $\alpha$-hANP at a dose of $5 \mu \mathrm{g}$ resulted in a transient increase in renal blood flow from $26.6 \pm 2.2$ to $33.7 \pm 2.2 \mathrm{ml} / \mathrm{min}(p<0.05)$ and a decrease in mean arterial pressure from $113 \pm 1.8$ to $107 \pm 2.2 \mathrm{mmHg}(p<$ 0.01 ). The calculated renal vascular resistance decreased from $4.50 \pm 0.34$ to $3.28 \pm 0.20 \mathrm{mmHg} / \mathrm{ml} / \mathrm{min}(p<0.05)$. This vasodilatory effect of $\alpha$-hANP was immediate and lasted for $30 \mathrm{~min}$. These hemodynamic alterations were not associated with the changes in glomerular filtration rate estimated by creatinine clearance. Intravenous injection of $\alpha$-hANP also produced marked increases in urine volume from $1.99 \pm 0.43$ to $5.7 \pm 1.20 \mathrm{ml} / 10 \mathrm{~min}(p<0.01)$, urinary sodium from $42.2 \pm 7.6$ to $243 \pm 54 \mu \mathrm{Eq} / 10 \mathrm{~min}(p<0.01)$, urinary potassium from $37.5 \pm$ 5.5 to $74.8 \pm 10.3 \mu \mathrm{Eq} / 10 \mathrm{~min}(p<0.01)$, and urinary kinin excretion from $3.44 \pm$ 0.49 to $5.26 \pm 0.82 \mathrm{ng} / 10 \mathrm{~min}(p<0.05)$. The observed natriuretic effect of $\alpha$ hANP lasted only for $30 \mathrm{~min}$, whereas diuretic and kaliuretic effects were sustained for $120 \mathrm{~min}$. Hematocrit levels did not change significantly throughout the experiment. These results indicate that $\alpha$-hANP is a potent vasodilator substance and that the natriuretic effect induced by the bolus injection of $\alpha$-hANP is mediated mainly through its renal vasodilatory action. It is also suggested that the renal kinin, at least in part, contributes to the natriuretic effect of $\alpha$-hANP.

$\alpha$-human atrial natriuretic polypeptide $(\alpha$-hANP); renal hemodynamics; fluid and electrolyte excretion; urinary kinin excretion
\end{abstract}

It is well informed that mammalian atrial extract when administered to rats produces a marked natriuresis and diuresis (de Bold et al. 1981 ; Briggs et al. 1982 ; Keeler and Azzarolo 1983 ; Pollock and Banks 1983 ; Camargo et al. 1984 ;

Received October 4, 1986; accepted for publication January 14, 1987. 
Beasley and Malvin 1985), but the effects of atrial extract on renal hemodynamics are controversial. Some studies have suggested an increase in renal blood flow (Keeler and Azzarolo 1983; Vaughan et al. 1983), and others have indicated no effect on renal blood flow (Keeler 1982 ; Pollock and Banks 1983 ; Beasley and Malvin 1985). These conflicts of the mechanism of action of atrial extract include use of crude, unpurified extracts of the right atrium that may contain contaminants. Recent purification, sequencing, and synthesis of atrial natriuretic substance extracted from rats or humans have resulted in the availability of new synthetic polypeptides composed of the 28 amino acids which are referred to as $\alpha$-rat (Kangawa and Matsuo 1984) or $\alpha$-human atrial natriuretic polypeptide (Kangawa et al.1984). These synthetic polypeptides have been thought to have the same biological activity as the native peptides, but the mechanisms by which $\alpha$-hANP produces a diuresis and natriuresis are still unclear. The present study was designed to examine the effects of intravenous injection of $\alpha$-hANP on blood pressure, renal hemodynamics, fluid and electrolyte excretion in anesthetized rabbits. We also examined a role of the renal kinin in $\alpha$-hANP-induced natriuresis, since it has been demonstrated that the renal kinin contributes to a potent natriuresis.

\section{Materials and Methods}

Experiments were performed on six female albino rabbits weighing $3.0-3.2 \mathrm{~kg}$. The animals were raised on standard rabbit chow which provided $9.1 \mathrm{mEq}$ sodium $/ 100 \mathrm{~g}$ and $63.4 \mathrm{mEq}$ potassium $/ 100 \mathrm{~g}$, and were allowed free access to water. The rabbits were fasted

\section{Protocol}
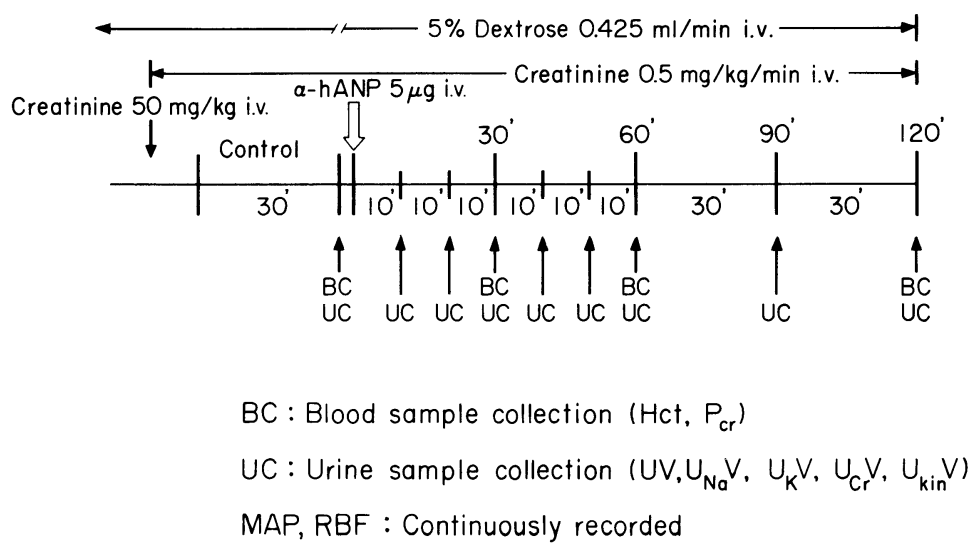

Fig. 1. Experimental protocol in the present experiments. MAP, mean arterial pressure; RBF, renal blood flow; Hct, arterial hematocrit; $\mathrm{P}_{\mathrm{cr}}$, plasma creatinine concentration; $\mathrm{UV}$, urine volume; $\mathrm{U}_{\mathrm{Na}} \mathrm{V}$, urinary sodium excretion; $\mathrm{U}_{\mathrm{K}} \mathrm{V}$, urinary potassium excretion; $\mathrm{U}_{\mathrm{cr}} \mathrm{V}$, urinary creatinine excretion ; $\mathrm{U}_{\mathrm{kin}} \mathrm{V}$, urinary kinin excretion. 
overnight $(20 \mathrm{hr})$ and water was allowed at libitum. The rabbits were anesthetized with urethan $(450 \mathrm{mg} / \mathrm{kg}$ i.v.) and $\alpha$-chloralose $(45 \mathrm{mg} / \mathrm{kg}$ i.v.). Tracheotomy was undergone and the trachea was intubated for spontaneous breathing. The left jugular vein was cannulated with polyethylene tubing (PE 50) and a catheter (PE 50) was inserted into the inferior vena cava through the left femoral vein for an infusion of $5 \%$ dextrose solution or injection of $\alpha$-hANP. A third polyethylene catheter (PE 60) was placed into the abdominal aorta adjacent to the renal arteries through the left femoral artery for arterial pressure recording and collection of arterial blood sample. The left renal artery was then exposed through a left peritoneal flank incision and gently isolated. A non-cannulating electromagnetic flow probe $(2.0 \mathrm{~mm}$, Nihon Kohden, Tokyo), connected to an electromagnetic flow meter (MF-27, Nihon Kohden), was placed around the renal artery for the monitoring of renal blood flow. Arterial pressure was monitored with a pressure transducer and amplifier (Biophysiograph, 180 system, San-ei, Tokyo), and recorded on a pen oscillograph with renal blood flow. The left ureter was then cannulated with tubing for collection of urine. Solution of $5 \%$ dextrose was infused intravenously to the extent of $2 \%$ of body weight as a priming infusion and then followed by a sustained infusion at a rate of $0.425 \mathrm{ml} / \mathrm{min}$ throughout the experiment. $\alpha$-Human atrial natriuretic polypeptide ( $\alpha$-hANP) (Protein Research Foundation, Osaka) stored at $-20^{\circ} \mathrm{C}$ was dissolved in distilled water to the appropriate concentration of $5 \mu \mathrm{g} / \mathrm{ml}$ for intravenous administration. After the completion of surgery, at least $60 \mathrm{~min}$ were allowed for stabilization of arterial blood pressure and renal blood flow. Then a priming dose of $50 \mathrm{mg} / \mathrm{kg}$ of creatinine in $4 \mathrm{ml} \mathrm{of} 5 \%$ dextrose solution was given through the left jugular vein catheter and was followed by a prolonged infusion of $0.5 \mathrm{mg} / \mathrm{kg} / \mathrm{min}$ in $0.425 \mathrm{ml} / \mathrm{min}$ of $5 \%$ dextrose solution throughout the experiment to determine glomerular filtration rate. Twenty min after the priming injection of creatinine, experimental protocol was started.

Fig. 1 illustrates the present experimental protocols. Each experiment consisted of a 30 -min control period at the end of which urine collection and $5 \mathrm{ml}$ of arterial blood sample were taken. Urine volume (UV), urinary excretion of sodium $\left(\mathrm{U}_{\mathrm{Na}} \mathrm{V}\right)$, potassium $\left(\mathrm{U}_{\mathrm{K}} \mathrm{V}\right)$, kinin $\left(\mathrm{U}_{\mathrm{kin}} \mathrm{V}\right)$ and creatinine $\left(\mathrm{U}_{\mathrm{cr}} \mathrm{V}\right)$, systemic arterial hematocrit (Hct), and plasma creatinine concentration $\left(\mathrm{P}_{\mathrm{cr}}\right)$, were determined as the controls. Then $\alpha$-hANP was inject-

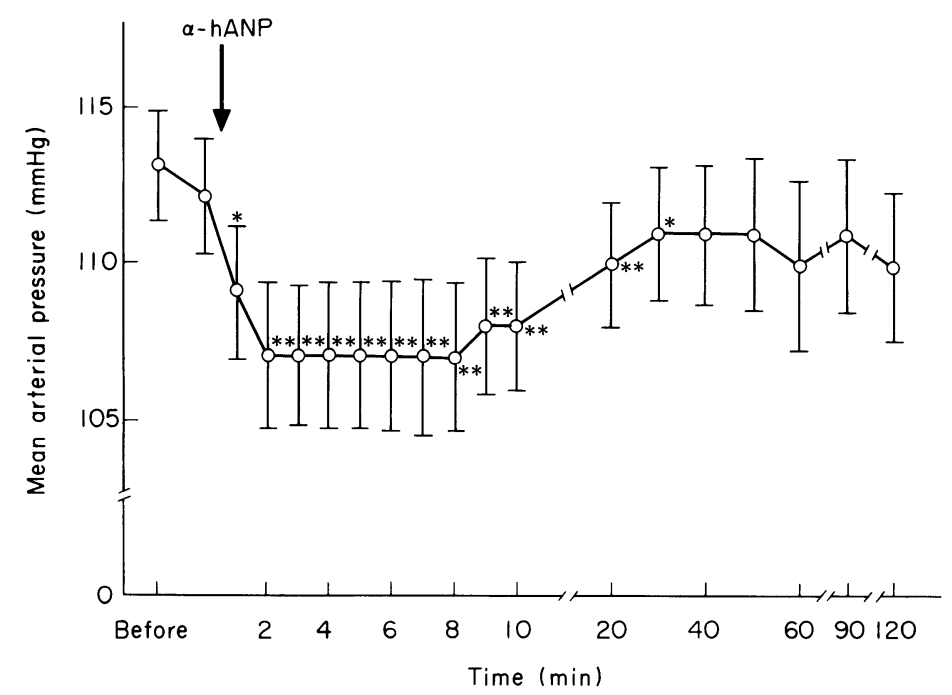

Fig. 2. Effect of intravenous injection of $\alpha$-human atrial natriuretic polypeptide on mean arterial pressure. ${ }^{*} p<0.05$ compared with before ${ }^{* *} p<0.01$ compared with before. 


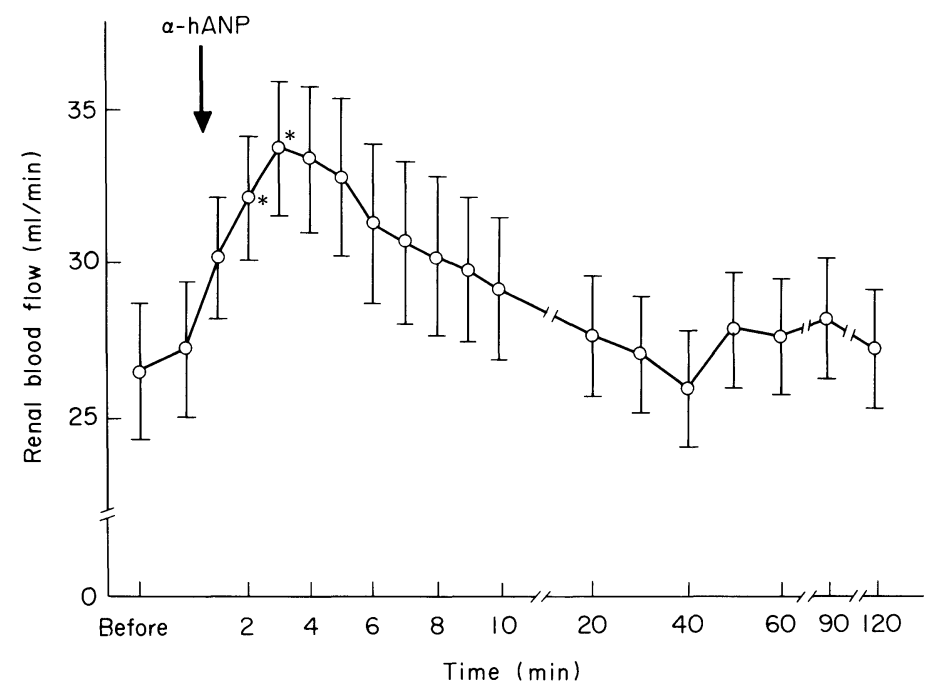

Fig. 3. Effect of intravenous injection of $\alpha$-human atrial natriuretic polypeptide on renal blood flow. ${ }^{*} p<0.05$ compared with before.

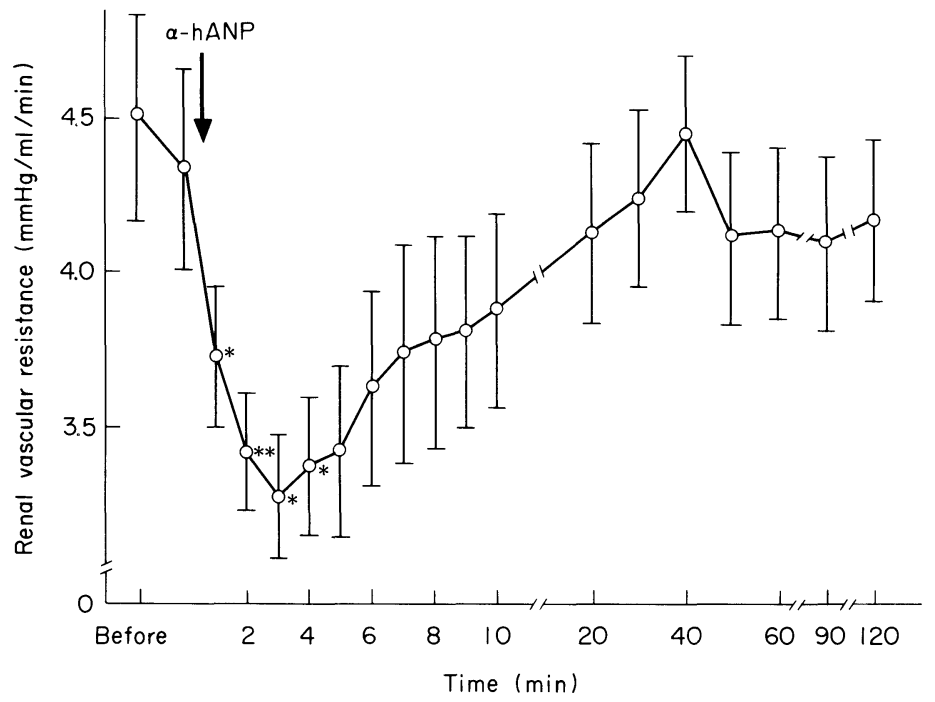

Fig. 4. Effect intravenous injection of $\alpha$-human atrial natriuretic polypeptide on renal vascular resistance. ${ }^{*} p<0.05$ compared with before. ${ }^{* *} p<0.01$ compared with before.

ed intravenously at a dose of $5 \mu \mathrm{g}$ through the femoral vein catheter. After the injection, six consecutive 10-min urine collections were taken, then two consecutive 30-min urine collections were followed. $\mathrm{UV}, \mathrm{U}_{\mathrm{Na}} \mathrm{V}, \mathrm{U}_{\mathrm{K}} \mathrm{V}, \mathrm{U}_{\mathrm{cr}} \mathrm{V}$ and $\mathrm{U}_{\mathrm{kin}} \mathrm{V}$, were also determined in each urine sample. Arterial blood samples were drawn at 30,60 and $120 \mathrm{~min}$ after the $\alpha$-hANP injection. After each blood sample collection, the same amount of arterial blood drawn from another donor rabbits was supplemented at the rate that did not have a volume effect on renal blood flow. Glomerular filtration rate was estimated from the clearance of 


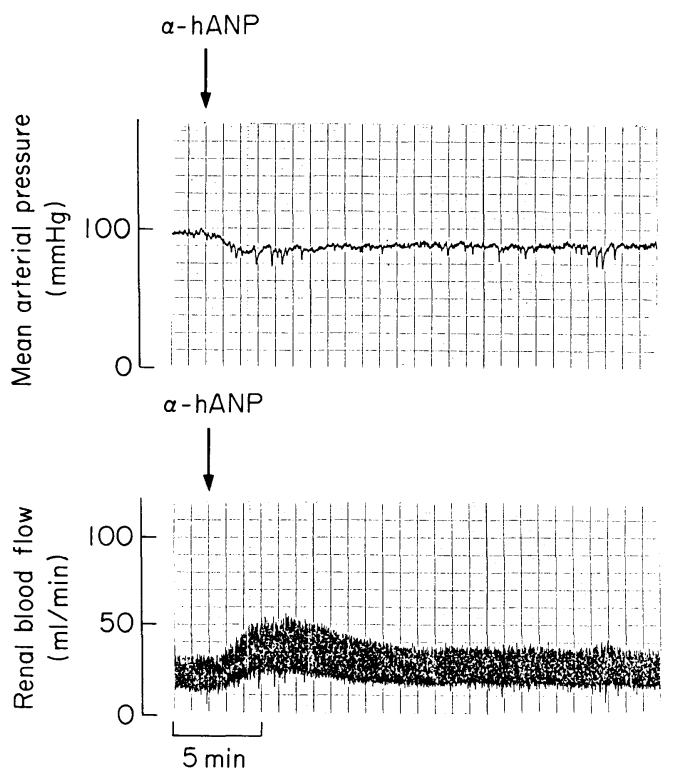

Fig. 5. Typical effects of intravenous injection of $\alpha$-human atrial natriuretic polypeptide $(\alpha$-hANP) on mean arterial pressure and renal blood flow.

creatinine. Plasma and urinary concentrations of creatinine were determined by cleanerlizer (VS-700 s, Nihon Denshi, Tokyo). Urinary concentrations of sodium and potassium were also determined by autoanalyzer (STAT/ION-II, Nihon Technicon, Tokyo). Urinary kinin concentration was measured by radioimmunoassay described elsewhere (Abe et al. 1978). Renal vascular resistance (RVR) was calculated by dividing mean arterial pressure by renal blood flow, and was expressed as $\mathrm{mmHg} / \mathrm{ml} / \mathrm{min}$.

$\mathrm{UV}, \mathrm{U}_{\mathrm{Na}} \mathrm{V}, \mathrm{U}_{\mathrm{K}} \mathrm{V}, \mathrm{U}_{\mathrm{cr}} \mathrm{V}$ and $\mathrm{U}_{\mathrm{kin}} \mathrm{V}$ excreted during the 30 -min period were expressed as average value for 10-min excretion.

All data in the control period were compared with those in the experimental period using Student's paired $t$ test. Statistical significance was considered to be $p<0.05$. All data in figures and tables are expressed as means \pm s.E.

\section{Results}

Figs. 2, 3. and 4 illustrate the effects of intravenous injection of $\alpha$-hANP on mean arterial pressure (MAP), renal blood flow (RBF), and renal vascular resistance (RVR), respectively.

MAP decreased significantly from $113 \pm 1.8$ to $109 \pm 2.1,107 \pm 2.3,108 \pm 2.1$, $110 \pm 2.1$ and $111 \pm 2.1 \mathrm{mmHg}$ at $1,2,5,10,20$ and $30 \mathrm{~min}$ after the $\alpha$-hANP injection, respectively. Then MAP gradually returned to the initial control level at $40 \mathrm{~min}$ after the injection of $\alpha$-hANP. As shown in Fig. 3, RBF increased markedly from $26.6 \pm 2.2$ to $32.1 \pm 2.0$ and $33.7 \pm 2.2 \mathrm{ml} / \mathrm{min}$ at 1 and $2 \mathrm{~min}$ after the $\alpha$-hANP injection, respectively, and returned slowly to the control level.

The calculated renal vascular resistance declined significantly from $4.50 \pm$ 
TABLE 1. Effect of intravenous injection of $\alpha$-human atrial natriuretic polypeptide on glomerular filtration rate (GFR)

\begin{tabular}{ccccc}
\hline & \multirow{4}{*}{ Control } & \multicolumn{4}{c}{ Time after injection (min) } \\
& & 30 & 60 & 120 \\
\hline GFR $(\mathrm{ml} / \mathrm{min})$ & $4.5 \pm 1.1$ & $4.3 \pm 0.4$ & $4.9 \pm 0.5$ & $4.7 \pm 0.8$ \\
\hline
\end{tabular}

Values are expressed as mean \pm s.E.

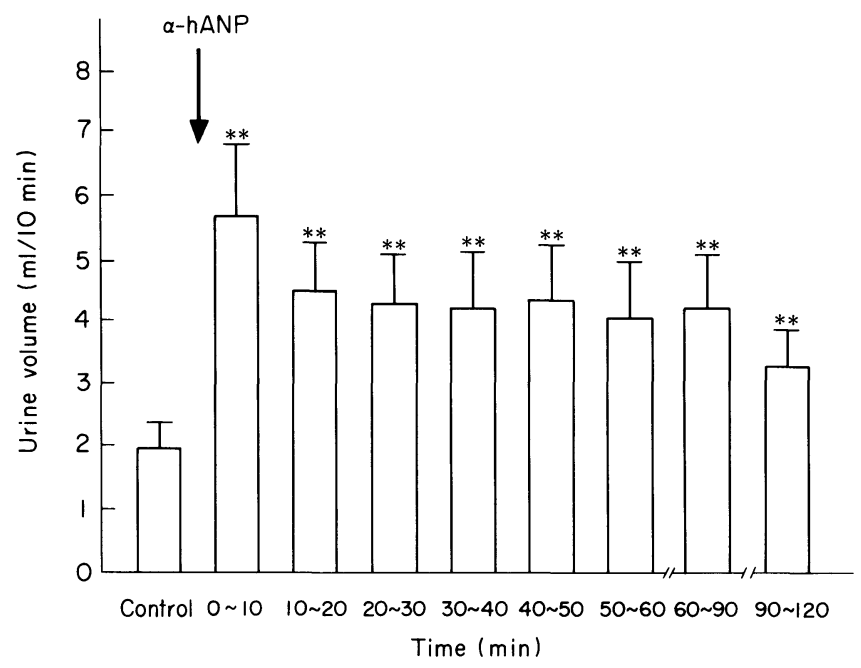

Fig. 6. Effect of intravenous injection of $\alpha$-human atrial natriuretic polypeptide on urine volume. ${ }^{* *} p<0.01$ compared with the control value.

0.34 to $3.73 \pm 0.22,3.42 \pm 0.18,3.28 \pm 0.20$ and $3.38 \pm 0.22 \mathrm{mmHg} / \mathrm{ml} / \mathrm{min}$ at $1,2,3$ and $4 \mathrm{~min}$ after the $\alpha$-hANP injection, and returned gradually to a control level (Fig. 4). Fig. 5 shows typical effects of intravenous injection of $\alpha$-hANP on MAP and RBF.

Changes in glomerular filtration rate (GFR) as estimated by creatinine clearance throughout the experiment are summarized in Table 1. GFR did not change significantly at either 30,60 , or 120 min after the $\alpha$-hANP injection as compared with the control value. Figs. 6,7 and 8 illustrate the effects of intravenous injection of $\alpha$-hANP on $\mathrm{UV}, \mathrm{U}_{\mathrm{Na}} \mathrm{V}$, and $\mathrm{U}_{\mathrm{K}} \mathrm{V}$, respectively. $\mathrm{UV}$ increased significantly from $1.99 \pm 0.43$ to $5.70 \pm 1.2 \mathrm{ml} / 10 \mathrm{~min}$ in the first $10 \mathrm{~min}$ period after the $\alpha$-hANP injection, and this significant increase in UV was sustained for 120 min. After the injection of $\alpha-\mathrm{hANP}, \mathrm{U}_{\mathrm{Na}} \mathrm{V}$ increased significantly from $42.2 \pm 7.6$ to $243 \pm 54(p<0.01), 143 \pm 25(p<0.01)$, and $83.2 \pm 12 \mu \mathrm{Eq} / 10 \mathrm{~min}(p<$ 0.01 ) at each period of 10,20 and $30 \mathrm{~min}$, respectively. $\mathrm{U}_{\mathrm{K}} \mathrm{V}$ also increased significantly from $37.5 \pm 5.5$ to $74.8 \pm 10 \mu \mathrm{Eq} / 10 \mathrm{~min}(p<0.01)$ in the first $10 \mathrm{~min}$ period after the injection of $\alpha$-hANP, and this significant increase in $\mathrm{U}_{\mathrm{K}} \mathrm{V}$ lasted to the end of the experiment. 


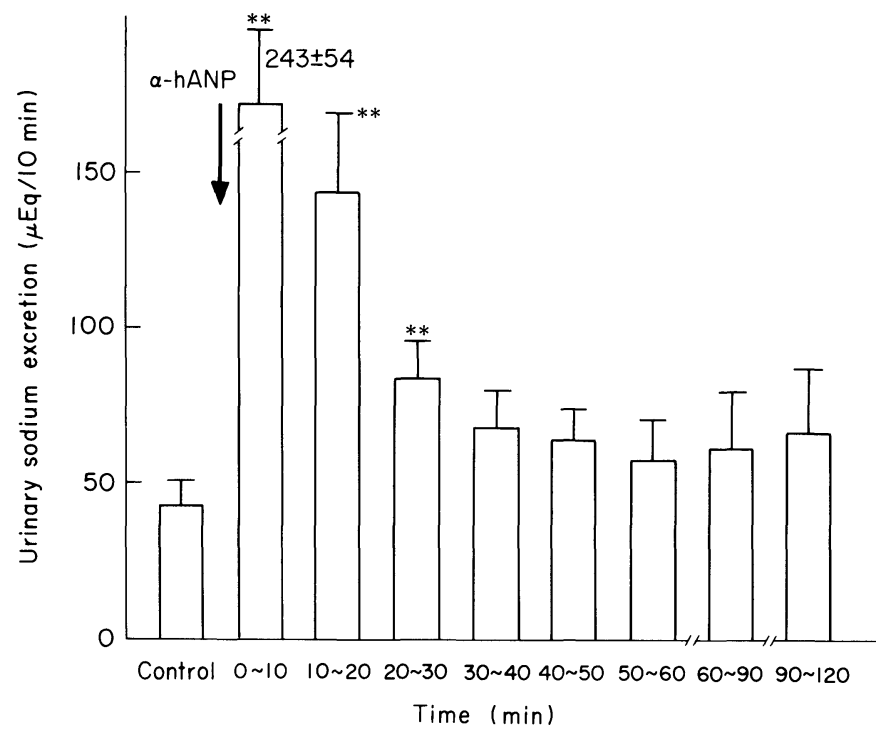

Fig. 7. Effect of intravenous injection of $\alpha$-human atrial natriuretic polypeptide on urinary sodium excretion. ${ }^{* *} p<0.01$ compared with the control value.

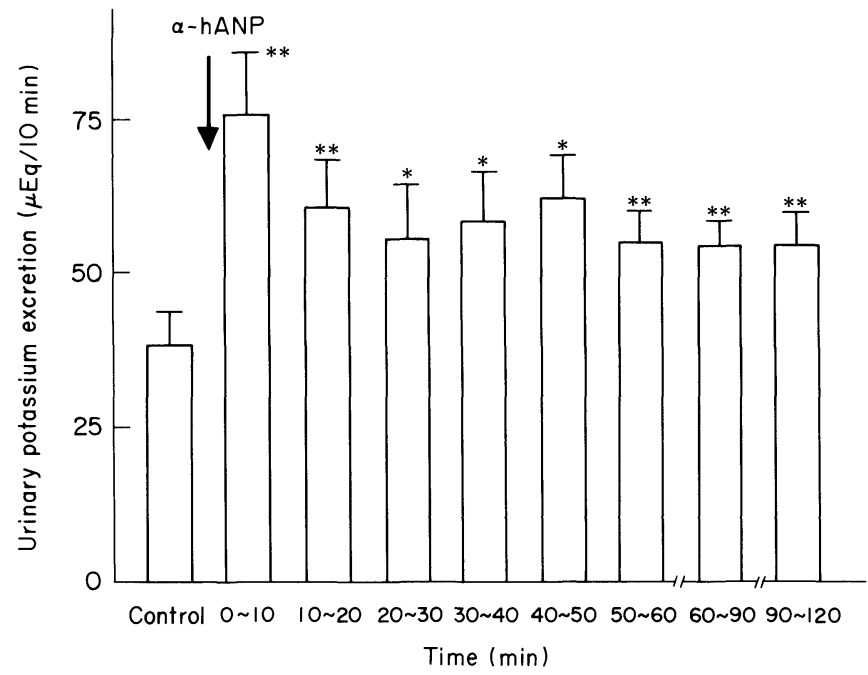

Fig. 8. Effect of intravenous injection of $\alpha$-human atrial natriuretic polypeptide on urinary potassium excretion. ${ }^{*} p<0.05$ compared with the control value. ${ }^{* *} p<0.01$ comapred with the control value.

Fig. 9 illustrates the effect of intravenous injection of $\alpha$-hANP on $\mathrm{U}_{\text {kin }} \mathrm{V}$. Intravenous injection of $\alpha$-hANP elicited a significant increase in $\mathrm{U}_{\mathrm{kin}} \mathrm{V}$ from a control value of $3.44 \pm 0.49$ to $5.26 \pm 0.82 \mathrm{ng} / 10 \mathrm{~min}(p<0.05)$ in the second $10 \mathrm{~min}$ period after the $\alpha$-hANP injection. This increase in $\mathrm{U}_{\text {kin }} \mathrm{V}$ by $\alpha$-hANP was sustained for $60 \mathrm{~min}$, and $\mathrm{U}_{\text {kin }} \mathrm{V}$ returned to the control level at $120 \mathrm{~min}$. 


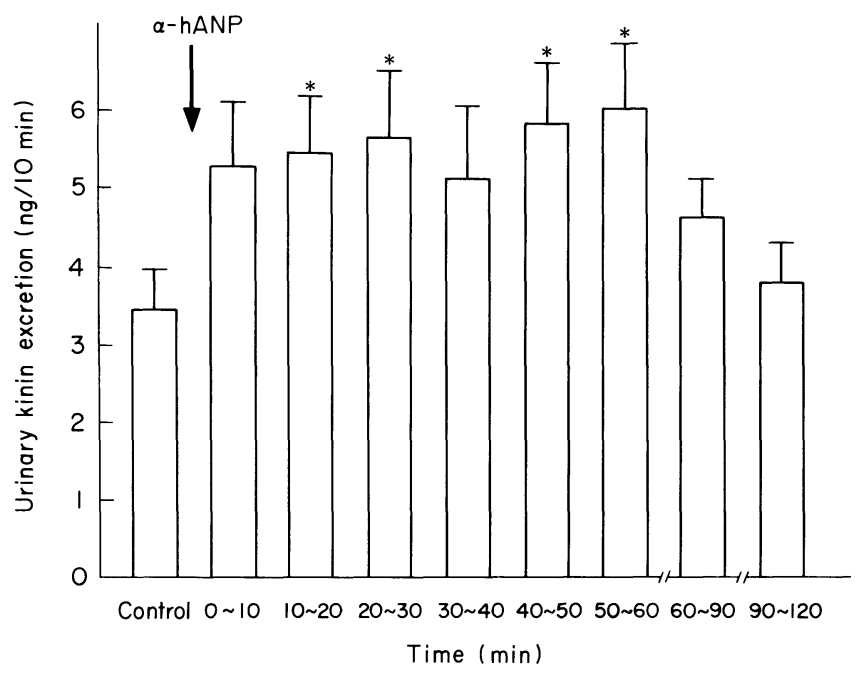

Fig. 9. Effect of intravenous injection of $\alpha$-human atrial natriuretic polypeptide on urinary kinin excretion. ${ }^{*} p<0.05$ compared with the control value.

\section{Discussion}

Intravenous injection of $\alpha$-hANP at a dose $5 \mu \mathrm{g}$ resulted in a significant decrease in MAP with a marked transient increase in RBF. These renal vasodilatory effects of $\alpha$-hANP are consistent with the observations by Keeler and Azzarolo (1983), Borenstein et al. (1983), Wakitani et al. (1985) and Hintze et al. (1985) that atrial extracts or atriopeptin II and III elicited renal vasodilation in anesthetized rats or dogs, or in conscious dogs. In the present experiment, the natriuretic effect of $\alpha$-hANP was not associated with changes in glomerular filtration rate estimated at $30 \mathrm{~min}$ after the injection of $\alpha$-hANP. However, glomerular filtration rate may have increased immediately after the intravenous injection of $\alpha$-hANP, and this increase in GFR may have been transient, therefore, resulting in failure of determination for a period of 30 min after the $\alpha$-hANP injection. In fact, Keeler and Azzarolo (1983) reported an increase in GFR only during the first 5-min period following the injection of atrial extract in spite of a fall in mean arterial pressure. There have been some different reports concerning the effects of atrial extracts on GFR. In in vivo studies in which atrial extracts have been reported to fail to affect GFR (de Bold et al. 1981; Keeler 1982 ; Sonnenberg et al. 1982 ; Nemeh and Gilmore 1983 ; Pollock and Banks 1983), a bolus injection of atrial extracts was given, and the subsequent natriuresis was both rapid in onset and transient. On the other hand, an increase in GFR was observed in studies in which atrial extract or atrial natriuretic factor was infused intrarenally or intravenously at a constant rate (Burnett et al. 1984 ; Maack et al. 1984 ; Beasley and Malvin 1985; Huang et al. 1985; Hammond et al. 1985 ; Hirata et al. 1985). Bolus injections of atrial extracts or atrial natriuretic factor 
lead to transient that could not be detected if the clearance period exceeds the transient time. In our present experiment, intravenous injection of $\alpha$-hANP might have resulted in a transient increase in GFR that could not have been detected in the 30-min period. Ultimately, we could not estimate the accurate changes in GFR produced by $\alpha$-hANP in the present experiment. However, we recently observed a significant increase in GFR by 24 and $28 \%$ at 30 and $60 \mathrm{~min}$ after an intravenous constant infusion of $\alpha$-hANP at a rate of $0.05 \mu \mathrm{g} / \mathrm{kg} / \mathrm{min}$ (Nushiro et al. unpublished data).

In the present study, intravenous injection of $\alpha$-hANP at a dose of $5 \mu \mathrm{g}$ resulted in a sustained increase in UV for $120 \mathrm{~min}$ and this increase in UV was associated with a sustained increase in $\mathrm{U}_{\mathrm{K}} \mathrm{V}$, whereas increased $\mathrm{U}_{\mathrm{Na}} \mathrm{V}$ elicited by the injection of $\alpha$-hANP was transient. It has been reported that intravenous injection of atrial extracts produces a diuresis and kaliuresis of short duration (de Bold et al. 1981 ; Borenstein et al. 1983 ; Keeler and Azzarolo 1983 ; Vaughan et al. 1983; Thibault et al. 1984). These discrepancies of duration of diuresis and kaliuresis between in our experiment and in others might have been caused by the different volume status of animals. In the present experiment, $5 \%$ dextrose solution was infused intravenously to the extent of $2 \%$ body weight as a priming infusion and then was followed by a sustained infusion at a rate of $0.425 \mathrm{ml} / \mathrm{min}$ during the experiment. Therefore, in our present experiment, the diuresis and kaliuresis might have been persistent for 120 min after the intravenous injection of $\alpha$-hANP. Another possible mechanism by which the prolonged diuresis and kaliuresis was produced by $\alpha$-hANP is medullary washout. Borenstein et al. (1983) reported that injection of atrial extract into anesthetized rats increased total and medullary blood flow in the kidney. In the present study, the prolonged kaliuresis was accompanied by the diuresis, which suggests that urine flow into the distal tubule may have increased after the injection of $\alpha$-hANP, since it has been shown that potassium secretion is increased when flow into the distal tubule is increased (Malnic et al. 1966; Morgan and Berliner 1969; Kunau et al. 1974 ; Khuri et al. 1975 ; Reineck et al. 1975; Diezi et al. 1976). This increase in urine flow into the distal tubule could have been elicited by the dissipation of corticomedullary osmotic gradient by medullary washout.

It has been demonstrated that the renal kinin possesses a potent natriuretic action. Therefore, we examined whether the renal kinin contributes to the natriuresis induced by $\alpha$-hANP, although it has been shown that kallikrein is a proteolytic factor of atrial natriuretic substance (Briggs et al. 1984; Thibault et al. 1984).

Intravenous injection of $\alpha$-hANP resulted in a significant increase in $\mathrm{U}_{\text {kin }} \mathrm{V}$. This increase in $\mathrm{U}_{\mathrm{kin}} \mathrm{V}$ was accompanied by the marked diuresis and natriuresis, and lasted for $60 \mathrm{~min}$. In the present study, it is not clear whether the kallikreinkinin system in the kidney contributed to the diuresis and natriuresis produced by $\alpha$-hANP, but since the renal kinin has been shown to have potent natriuretic 
action, it seems likely that the renal kinin, at least in part, contributes to the natriuresis produced by $\alpha$-hANP, and that the renal kallikrein-kinin system is not a proteolytic factor in vivo.

In summary, intravenous injection of $\alpha$-hANP resulted in a transient increase in $\mathrm{RBF}$ and in a decrease in MAP. These hemodynamic alterations were accompanied by a marked diuresis and natriuresis, and an increase in $\mathrm{U}_{\text {kin }} \mathrm{V}$.

These results suggest that $\alpha$-hANP is a potent renal vasodilator substance and that the natriuretic effect of $\alpha$-hANP is mediated primarily through the renal vasodilatory action, although the contribution of the renal kinin is not excluded completely.

\section{Acknowledgments}

We gratefully acknowledge the excellent technical assistance of Keiko Shiraishi.

This work was supported by Grants-in-Aid for Cardiovascular Disease from the Ministry of Health and Welfare of Japan (60-3).

\section{References}

1) Abe, K., Irokawa, N., Yasujima, M., Seino, M., Chiba, S., Sakurai, Y., Yoshinaga, K. \& Saito, T, (1978) The kallikrein-kinin system and prostaglandins in the kidney. Their relation to furosemide-induced diuresis and to the renin-angiotensin-aldosterone system in man. Circulat. Res., 43, 254-260.

2) Beasley, D. \& Malvin, R.L. (1985) Atrial extracts increase glomerular filtration in vivo. Amer. J. Physiol., 248, F24-F30.

3) de Bold, A.J., Borenstein, H.B., Veress, A.T. \& Sonnenberg, H. (1981) A rapid and potent natriuretic response to intravenous injection of atrial myocardial extract in rats. Life Sci., 28, 89-94.

4) Borenstein, H.B., Cupples, W.A., Sonnenberg, H. \& Veress, A.T. (1983) The effect of a natriuretic atrial extract on renal haemodynamics and urinary excretion in anesthetized rats. J. Physiol. (Lond.), 334, 133-140.

5) Briggs, J.P., Steipe, B., Schubert, G. \& Schnermann, J. (1982) Micropuncture studies of the renal effects of atrial natriuretic substance. Pflügers Arch., 395, 271-276.

6) Briggs, J.P., Marin-Grez, M., Steipe, B., Schubert, G. \& Schnermann, J. (1984) Inactivation of atrial natriuretic substance by kallikrein. Amer. J. Physiol., 247, F480-F484.

7) Burnett, J.C., Jr., Granger, J.P. \& Opgenorth, T.J. (1984) Effects of synthetic atrial natriuretic factor on renal function and renin release. Amer. J. Physiol., 247, F863F866.

8) Camargo, M.J.F., Kleinert, H.D., Atlas, S.A., Sealey, J.E., Laragh, J.H. \& Maack, T. (1984) Ca-dependent hemodynamic and natriuretic effects of atrial extract in isolated rat kidney. Amer. J. Physiol., 246, F447-F456.

9) Diezi, J., Michoud, P., Grandchamp, A. \& Giebisch, G. (1976) Effects of nephrectomy on renal salt and water transport in the remaining kidney. Kidney int., 10, 450-462.

10) Hammond, T.G., Yusufi, A.N., Knox, F.G. \& Dousa, T.P. (1985) Administration of atrial natriuretic factor inhibits sodium-coupled transport in proximal tubules. $J$. clin. Invest., 75, 1983-1989.

11) Hintze, T.H., Currie, M.G. \& Needleman, P. (1985) Atriopeptins: Renal-specific vasodilators in conscious dogs. Amer. J. Physiol., 248, H587-H591.

12) Hirata, Y., Ishii, M., Sugimoto, T., Matsuoka, H., Sugimoto, T., Kangawa, K. \& Matsuo, H. (1985) The effects of human atrial 28-amino acid peptide on systemic and 
renal hemodynamics in anesthetized rats. Circulat. Res., 57, 634-639.

13) Huang, C.L., Lewicki, J., Lohnson, L.K. \& Cogan, M.G. (1985) Renal mechanism of action of rat atrial natriuretic factor. $J$. clin. Invest., 75, 769-773.

14) Kangawa, K. \& Matsuo, H. (1984) Purification and complete amino acid sequence of $\alpha$-human atrial natriuretic polypeptide $(\alpha$-hANP). Biochem. biophys. Res. Commun., 118, 131-139.

15) Kangawa, K., Fukuda, A., Kubota, I., Hayashi, Y. \& Matsuo, H. (1984) Identification in rat atrial tissue of multiple forms of natriuretic polypeptides of about 3,000 daltons. Biochem. biophys. Res. Commun., 121, 585-591.

16) Keeler, R. (1982) Atrial natriuretic factor has a direct, prostaglandin-independent action on kidneys. Canad. J. Physiol. Pharmacol., 60, 1078-1082.

17) Keeler, R. \& Azzarolo, A.M. (1983) Effects of atrial natriuretic factor on renal handling of water and electrolytes in rats. Canad. J. Physiol. Pharmacol., 61, 9961002.

18) Khuri, R.N., Wiederholt, M., Strieder, N. \& Giebisch, G. (1975) Effects of flow rate and potassium intake on distal tubular potassium trasfer. Amer. J. Physiol., 228, 1249-1261.

19) Kunau, R.T., Webb, H.L. \& Borman, S.C. (1974) Characteristics of the relationship between the flow rate of tubular fluid and potassium transport in the distal tubule of the rat. J. clin. Invest., 54, 1488-1495.

20) Maack, T., Marion, D.N., Camargo, M.J.F., Kleinert, H.D., Laragh, J.H., Vaughan, E. D. \& Atlas, S.A. (1984) Effects of auriculin (atrial natriuretic factor) on blood pressure, renal function, and the renin-aldosterone system in dogs. Amer. J. Med., 77, 1069-1075.

21) Malnic, G., Klose, R.M. \& Giebisch, G. (1966) Micropuncture study of distal tubular potassium and sodium transport in rat nephron. Amer. J. Physiol., 211, 529-547.

22) Morgan, T. \& Berliner, R.W. (1969) A study by continuous microperfusion of water and electrolyte movements in the loop of Henle and distal tubule of the rat. Nephron, 6, 388-405.

23) Nemeh, M.N. \& Gilmore, J.P. (1983) Natriuretic activity of human and monkey atria. Circulat. Res., 53, 420-423.

24) Pollock, D.M. \& Banks, R.O. (1983) Effect of atrial extract on renal function in the rat. Clin. Sci., 65, 47-55.

25) Reineck, H.J., Osgood, R.W., Ferris, T.F. \& Stein, J.H. (1975) Potassium transport in the distal tubule and collecting duct of the rat. Amer. J. Physiol., 229, 1403-1409.

26) Sonnenberg, H., Cupples, W.A., de Bold, A.J. \& Veress, A.T. (1982) Intrarenal localization of the natriuretic effect of cardiac atrial extract. Canad. J. Physiol. Pharmacol., 60, 1149-1152.

27) Thibault, G., Garcia, R., Cantin, M. \& Genest, J. (1984) Atrial natriuretic factor and urinary kallikrein in the rat: Antagonistic factors? Canad. J. Physiol. Pharmacol., 62, 645-649.

28) Vaughan, E.D., Marion, D.H., Sealey, J.E., Camargo, M.J.F., Kleinert, H.D., Maack, T. \& Laragh, J.H. (1983) Atrial natriuretic extract: Effects on renal hemodynamics in the rabbit. Surg. Forum, 34, 690-692.

29) Wakitani, K., Cole, B.R., Geller, D.M., Currie, M.G., Adams, S.P., Fok, K.F. \& Needleman, P. (1985) Atriopeptins: Correlation between renal vasodilation and natriuresis. Amer. J. Physiol., 249, F49-F53. 